\title{
Ischemic Stroke Due to Paradoxical Embolism in a Patient with Patent Foramen Ovale, Bilateral Distal Deep Vein Thrombosis and Platypnea-Orthodeoxia Syndrome: A Case Report
}

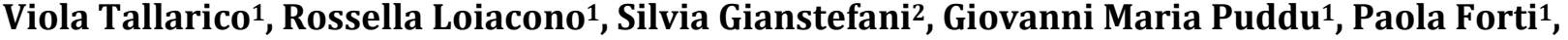 \\ Marco Zoli'
}

${ }^{1}$ Stroke Unit, Department of Internal Medicine, IRCCS Policlinico Sant'Orsola-Malpighi, Bologna, Italy

${ }^{2}$ Department of Cardiology, IRCCS Policlinico Sant'Orsola-Malpighi, Bologna, Italy

Email: viola.tallarico@studio.unibo.it

How to cite this paper: Tallarico, V., Loiacono, R., Gianstefani, S., Puddu, G.M., Forti, P. and Zoli, M. (2021) Ischemic Stroke Due to Paradoxical Embolism in a Patient with Patent Foramen Ovale, Bilateral Distal Deep Vein Thrombosis and Platypnea-Orthodeoxia Syndrome: A Case Report. World Journal of Cardiovascular Diseases, 11, 477-483.

https://doi.org/10.4236/wjcd.2021.1110045

Received: September 18, 2021

Accepted: October 25, 2021

Published: October 28, 2021

Copyright $\odot 2021$ by author(s) and Scientific Research Publishing Inc. This work is licensed under the Creative Commons Attribution International License (CC BY 4.0).

http://creativecommons.org/licenses/by/4.0/

\begin{abstract}
Patent foramen ovale (PFO) is a common congenital cardiac defect. It is usually asymptomatic, but it can be associated with relevant clinical manifestations such as cryptogenic stroke and platypnea-orthodeoxia syndrome. We present the case of a patient with hemodynamically significant carotid artery stenosis who underwent endarterectomy for a transient ischemic attack (TIA). After surgery, the patient presented an ischemic stroke due to M2 occlusion treated with mechanical thrombectomy. During hospitalization, a distal bilateral deep vein thrombosis was found. The patient developed respiratory failure due to a massive right-to-left shunt through a large PFO (platypnea-orthodeoxia syndrome). These findings are consistent with the hypothesis that the TIA and the subsequential ischemic stroke were related to paradoxical embolism rather than atherothromboembolism. The aim of our case report is to raise awareness of the possible complications of such a common finding as PFO.
\end{abstract}

\section{Keywords}

Patent Foramen Ovale, Cryptogenic Stroke, Paradoxical Embolism, Platypnea-Orthodeoxia Syndrome

\section{Introduction}

Patent foramen ovale (PFO) is a common congenital cardiac defect involving 
near $25 \%$ of the general population [1]. It is often diagnosed incidentally in asymptomatic patients, but it could be also associated with a variety of clinical manifestations, such as cryptogenic stroke and platypnea-orthodeoxia syndrome [2] [3].

Cryptogenic stroke is defined as a stroke that occurs in the absence of an identified cardioembolic or large vessel source, and with a distribution that is not consistent with small vessel disease. Most of these strokes are embolic, with paradoxical embolism through a PFO being a possible cause. In patients who suffered from cryptogenic stroke, the prevalence of PFO is $40 \%$ to $50 \%$ [1] [4] [5]. Recent randomized controlled trials and metanalysis have demonstrated that PFO closure in patients with cryptogenic stroke is associated with reduced rate of recurrent stroke, especially in patients with certain echocardiographic features (i.e., atrial septal aneurysm or large shunt) [6] [7] [8] [9] [10].

Platypnea-orthodeoxia syndrome is a rare disorder characterized by dyspnea and arterial desaturation in the upright position that improves with recumbency. Hypoxia occurs because deoxygenated venous blood mixes with the oxygenated arterial blood through a shunt. The site of the shunt can be classified into intracardiac or extracardiac, with PFO being the most common site of intracardiac shunt. Percutaneous closure of the defect is the treatment of choice [3] [11].

The aim of our case report is to raise awareness of the possible clinical manifestation and complications of such a common finding as PFO.

\section{Case Presentation}

We present the case of an 84-year-old woman who was admitted to hospital for a transient ischemic attack (TIA). She was affected by hypertension and hypercholesterolemia, and she was diagnosed with mild congenital pulmonary valve stenosis with severe post-stenosis pulmonary arteries dilatation. In 2012 she suffered a cryptogenic stroke treated with fibrinolysis, on treatment with acetylsalicylic acid for secondary prevention; during the hospitalization a PFO, with moderate right-to-left shunt, was found. At that time no indication for closure was given.

She was admitted to the Emergency Department for transient aphasia. The CT angiography of carotid arteries showed a left carotid bifurcation stenosis of 70\%, therefore a left carotid endarterectomy was performed.

The first day post-surgery, the neurological examination showed aphasia, dysarthria, right partial facial palsy, right arm weakness, right hemianopia (NIHSS 10). Multimodal brain CT scan documented hypoperfusion in the left middle cerebral artery territory due to M2 occlusion. Therefore, the patient underwent primary mechanical thrombectomy, with complete vascular recanalization and improvement of the neurological deficit (NIHSS 4).

After thrombectomy she was transferred to the Stroke Unit.

On admission the patient was apyretic, the arterial pressure was $170 / 80 \mathrm{mmHg}$, heart rate $70 / \mathrm{min}$, arterial saturation $97 \%$ with Venturi mask $\left(\mathrm{FiO}_{2} 31 \%\right)$. 
Antiplatelet therapy with clopidogrel was administered and physical and logopedic rehabilitation was performed with improvement in strength deficit and stability of language disorder.

A venous Eco Doppler, requested for left leg swelling, showed a bilateral distal deep vein thrombosis (DVT). The CT pulmonary angiogram ruled out pulmonary embolism, congestive heart failure, interstitial disease, and pneumonia. Anticoagulation with low dose of LMWH (enoxaparin 4000 IU bid) was administered in consideration of the recent surgery, the need of antiplatelet therapy, the high risk of intracranial hemorrhage, and the distal localization of the DVT.

The following week, the hospitalization was complicated by frequent episodes of severe respiratory failure (arterial saturation of $65 \%-70 \%$ with oxygen Venturi mask, in sitting position), treated with oxygen therapy with reservoir and continuous positive airways pressure (CPAP); this was associated with marked reduction in arterial blood pressure. During these episodes, the patient remained asymptomatic.

A second CT pulmonary angiogram excluded pulmonary embolism, and a cerebral CT scan ruled out new acute cerebral events. Brain natriuretic peptide (BNP), blood count, reactive C-protein (RCP) and procalcitonin (PCT) were in normal range. Four nasopharyngeal swabs and serology for SARS-CoV-2 were negative.

We evaluated oxygen saturation in upright and supine position, documenting desaturation in upright position and improvement of saturation values in supine position (platypnea-orthodeoxia syndrome) which could be related to an increasing right-to-left shunt through the PFO. Finally, a bubble study by transthoracic echocardiography was performed with agitated saline injected in the patient's right antecubital vein (Figures 1-4). The exam confirmed our hypothesis showing a massive right-to-left shunt through the PFO.

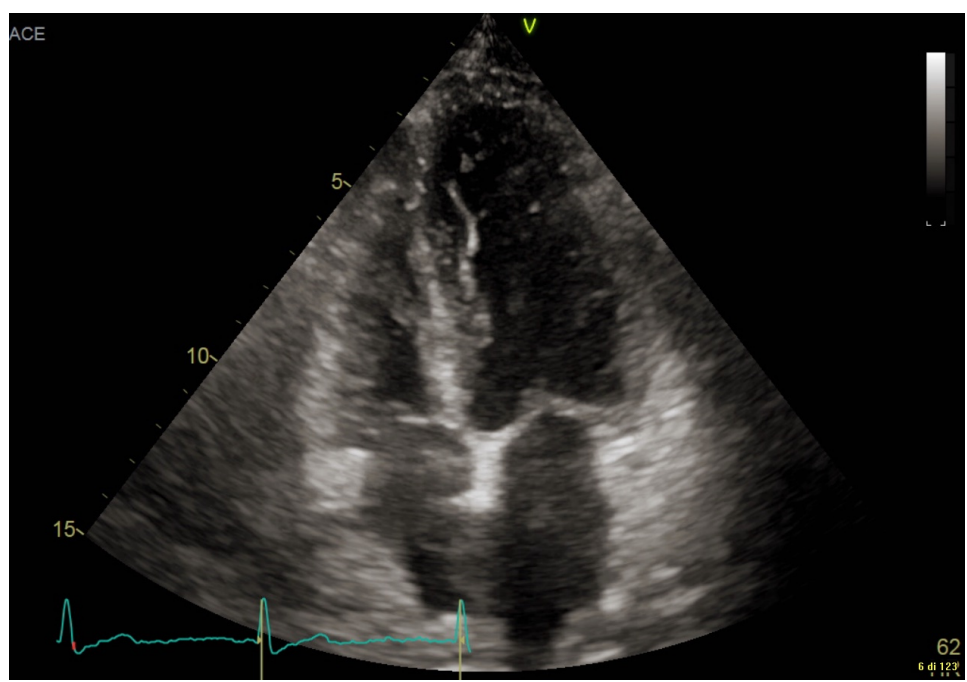

Figure 1. Apical four chamber echocardiogram view in resting conditions before the bubble injection. We can see the left atrium on the right bottom, the right atrium on the left bottom, the left ventricle on the right top and the right ventricle on the left top. 


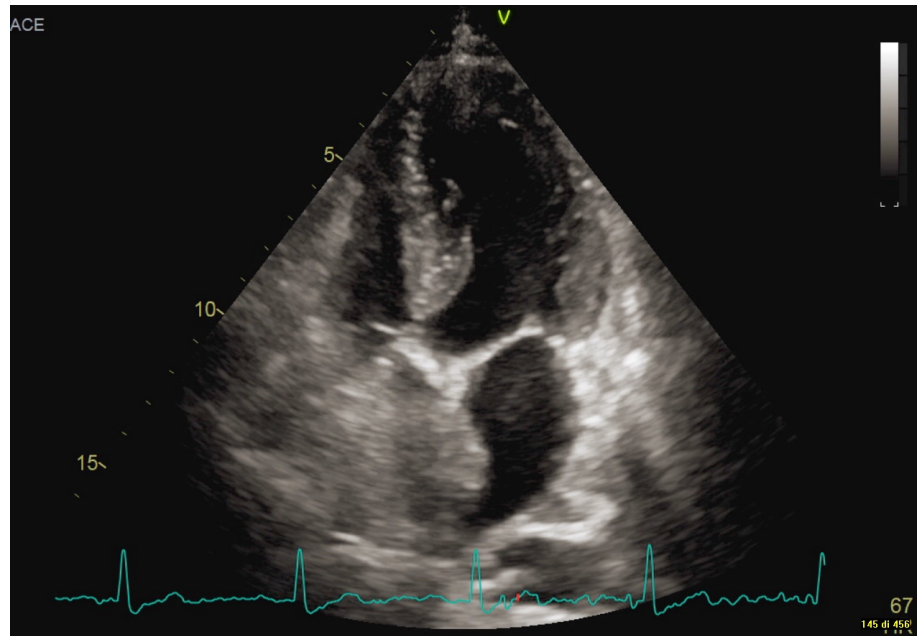

Figure 2. Opacization of the right atrium by the microbubbles.

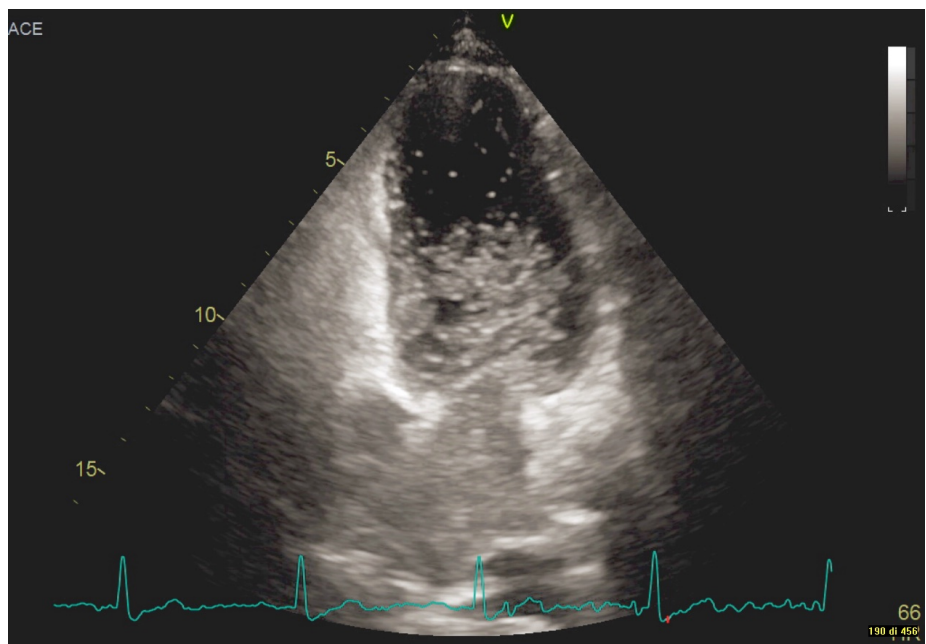

Figure 3. Microbubbles fill the right atrium and the right ventricle; many of them have already crossed the interatrial septum and can be seen in the left ventricular cavity.

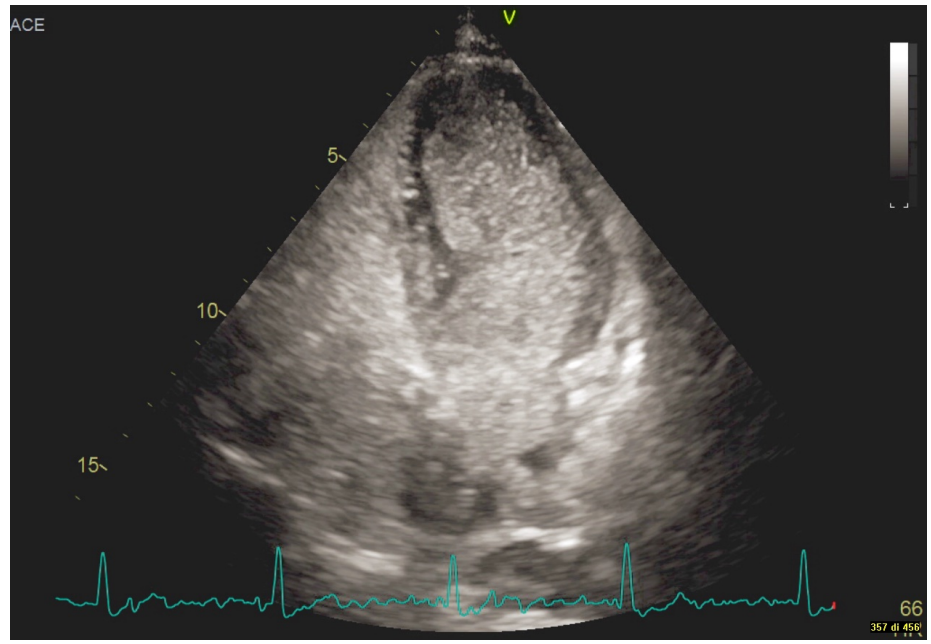

Figure 4. Atria and ventricles filled by microbubbles demonstrating a massive right-to-left shunt. 
The patient was transferred to the Cardiology Department to evaluate the possibility of PFO closure. Unfortunately, before the closure the patient developed a fatal septic shock complicated by multi organ failure.

\section{Discussion}

This case report shows two relevant complications of PFO.

Our patient underwent carotid surgery for a TIA, subsequently developing an ischemic stroke. Given the finding of a distal bilateral DVT and the presence of a PFO complicated by right-to-left shunt, we can speculate that the ischemic events were likely to be related to paradoxical embolism rather than atherothromboembolism.

The patient also presented a rare cause of respiratory failure associated to the presence of a PFO: platypnea-orthodeoxia syndrome. In this case, the shunting was exacerbated by a congenital pulmonary valve stenosis and likely by the recent surgery, as the patient never manifested acute respiratory failure before hospitalization.

Cryptogenic stroke caused by paradoxical embolism and platypnea-orthodeoxia syndrome are both well described complications of PFO, but case reports of their coexistence in the same patient are few [12] [13] [14] [15]. Noticeably, all these previous reports underline the efficacy of PFO closure on relieving respiratory symptoms and preventing new cerebral ischemic events.

At present, the "European position paper on the management of patients with patent foramen ovale" [16] declares that the management of all PFO-associated syndromes should be based on an interdisciplinary collaboration, and the decision making should take into account the probability of a causal role of the PFO in the clinical picture and the risk of recurrence. Given the massive right-to-left shunt, our patient would have probably benefited from PFO closure. However, she died due to an infectious complication before the closure had been performed.

\section{Conclusion}

Although usually asymptomatic, PFO could be related to severe complications. In this case report, the patient manifested two PFO-associated syndromes: cryptogenic stroke caused by paradoxical embolism and platypnea-orthodeoxia syndrome. PFO closure has been demonstrated to be effective in preventing new ischemic events and relieving respiratory failure.

\section{Informed Consent}

Informed consent was acquired from the patient's family.

\section{Conflicts of Interest}

The authors declare that there is no conflict of interest. 


\section{References}

[1] Hara, H., Virmani, R., Ladich, E., Mackey-Bojack, S., Titus, J., Reisman, M., et al. (2005) Patent Foramen Ovale: Current Pathology, Pathophysiology, and Clinical Status. Journal of the American College of Cardiology, 46, 1768-1776. https://doi.org/10.1016/j.jacc.2005.08.038

[2] Mojadidi, M.K., Zaman, M.O., Elgendy, I.Y., Mahmoud, A.N., Patel, N.K., Agarwal, N., Tobis, J.M., et al. (2018) Cryptogenic Stroke and Patent Foramen Ovale. Journal of the American College of Cardiology, 71, 1035-1043.

https://doi.org/10.1016/j.jacc.2017.12.059

[3] Agrawal, A., Palkar, A. and Talwar, A. (2017) The Multiple Dimensions of Platypnea-Orthodeoxia Syndrome: A Review. Respiratory Medicine, 129, 31-38. https://doi.org/10.1016/j.rmed.2017.05.016

[4] Lechat, P., Mas, J.L., Lascault, G., Loron, P., Theard, M., Klimczac, M., et al. (1988) Prevalence of Patent Foramen Ovale in Patients with Stroke. The New England Journal of Medicine, 318, 1148-1152. https://doi.org/10.1056/NEJM198805053181802

[5] Webster, M.W., Chancellor, A.M., Smith, H.J., Swift, D.L., Sharpe, D.N., Bass, N.M., et al. (1988) Patent Foramen Ovale in Young Stroke Patients. The Lancet, 2, 11-12. https://doi.org/10.1016/S0140-6736(88)92944-3

[6] Furlan, A.J., Reisman, M., Massaro, J., Mauri, L., Adams, H., Albers, G.W., et al. (2012) Closure or Medical Therapy for Cryptogenic Stroke with Patent Foramen Ovale. The New England Journal of Medicine, 366, 991-999. https://doi.org/10.1056/NEJMoa1009639

[7] Saver, J.L., Carroll, J.D., Thaler, D.E., Smalling, R.W., MacDonald, L.A., Marks, D.S., et al. (2017) Long-Term Outcomes of Patent Foramen Ovale Closure or Medical Therapy after Stroke. The New England Journal of Medicine, 377, 1022-1032. https://doi.org/10.1056/NEJMoa1610057

[8] Khan, A.R., Bin Abdulhak, A.A., Sheikh, M.A., Khan, S., Erwin, P.J., Tleyjeh, I., et al. (2013) Device Closure of Patent Foramen Ovale versus Medical Therapy in Cryptogenic Stroke: A Systematic Review and Meta-Analysis. JACC: Cardiovascular Interventions, 6, 1316-1323. https://doi.org/10.1016/j.jcin.2013.08.001

[9] Rengifo-Moreno, P., Palacios, I.F., Junpaparp, P., Witzke, C.F., Morris, D.L. and Romero-Corral, A. (2013) Patent Foramen Ovale Transcatheter Closure vs. Medical Therapy on Recurrent Vascular Events: A Systematic Review and Meta-Analysis of Randomized Controlled Trials. European Heart Journal, 34, 3342-3352.

https://doi.org/10.1093/eurheartj/eht285

[10] Hornung, M., Bertog, S.C., Franke, J., Id, D., Taaffe, M., Wunderlich, N., et al. (2013) Long-Term Results of a Randomized Trial Comparing Three Different Devices for Percutaneous Closure of a Patent Foramen Ovale. European Heart Journal, 34, 3362-3369. https://doi.org/10.1093/eurheartj/eht283

[11] Shah, A.H., Osten, M., Leventhal, A., Bach, Y., Yoo, D., Mansour, D., et al. (2016) Percutaneous Intervention to Treat Platypnea-Orthodeoxia Syndrome: The Toronto Experience. JACC: Cardiovascular Interventions, 9, 1928-1938. https://doi.org/10.1016/j.jcin.2016.07.003

[12] Madonna, R., Cresti, A. and Mancuso, M. (2011) Can Patent Foramen Ovale Affect Rehabilitation? The Uncommon Association of Platypnea-Orthodeoxia Syndrome and Stroke. Neurological Sciences, 32, Article No. 513. https://doi.org/10.1007/s10072-011-0572-x 
[13] Floria, M., Gabriel, L., Schroeder, E., Chenu, P., Ambăruş, V. and Marchandise, B. (2012) Stroke and an Unexplained Dyspnea in an Elderly Patient: Platypnea-Orthodeoxia Syndrome. Geriatrics \& Gerontology International, 12, 356-358. https://doi.org/10.1111/j.1447-0594.2011.00758.x

[14] Takashima, N., Suzuki, T., Asai, T. and Hosoba, S. (2012) Successful Surgical Repair of Platypnea-Orthodeoxia Syndrome in a Patient with Cerebral Infarction. Interactive Cardio Vascular and Thoracic Surgery, 15, 178-180.

https://doi.org/10.1093/icvts/ivs105

[15] Angelini, M., Lambru, G., Montepietra, S., Riccardi, M., Zanferrari, C. and Bortone, E. (2010) Unexplained Dyspnea in an Old Patient with Recurrent Stroke: Platypnea-Orthodeoxia Syndrome and Evidence of Patent Foramen Ovale. Neurological Sciences, 31, 93-94. https://doi.org/10.1007/s10072-009-0169-9

[16] Pristipino, C., Sievert, H., D’Ascenzo, F., Mas, J.L., Meier, B., Scacciatella, P., Hildick-Smith, D., Gaita, F., Toni, D., Kyrle, P., Thomson, J., Derumeaux, G., Onorato, E., Sibbing, D., Germonpré, P., Berti, S., Chessa, M., Bedogni, F., Dudek, D., Hornung, M., Zamorano, J., European Association of Percutaneous Cardiovascular Interventions (EAPCI), European Stroke Organisation (ESO), European Heart Rhythm Association (EHRA), European Association for Cardiovascular Imaging (EACVI), Association for European Paediatric and Congenital Cardiology (AEPC), ESC Working Group on GUCH, ESC Working Group on Thrombosis and European Haematological Society (EHA) (2019) European Position Paper on the Management of Patients with Patent Foramen Ovale. General Approach and Left Circulation Thromboembolism. EuroIntervention, 14, 1389-1402.

https://doi.org/10.4244/EIJ-D-18-00622 